\title{
Identifying 'unhealthy' food advertising on television: a case study applying the UK Nutrient Profile model
}

\author{
Gabrielle Jenkin*, Nick Wilson and Nicole Hermanson \\ Department of Public Health, Health Promotion \& Policy Research Unit, University of Otago, Wellington, \\ PO Box 7343, Wellington South, New Zealand
}

Submitted 26 November 2007: Accepted 2 May 2008: First published online 11 July 2008

\begin{abstract}
Objectives: To evaluate the feasibility of the UK Nutrient Profile (NP) model for identifying 'unhealthy' food advertisements using a case study of New Zealand television advertisements.

Design: Four weeks of weekday television from 15.30 hours to 18.30 hours was videotaped from a state-owned (free-to-air) television channel popular with children. Food advertisements were identified and their nutritional information collected in accordance with the requirements of the NP model. Nutrient information was obtained from a variety of sources including food labels, company websites and a national nutritional database.

Results: From the $60 \mathrm{~h}$ sample of weekday afternoon television, there were 1893 advertisements, of which 483 were for food products or retailers. After applying the NP model, $66 \%$ of these were classified as advertising high-fat, high-salt and high-sugar (HFSS) foods; $28 \%$ were classified as advertising non-HFSS foods; and the remaining $2 \%$ were unclassifiable. More than half $(53 \%)$ of the HFSS food advertisements were for 'mixed meal' items promoted by major fast-food franchises. The advertising of non-HFSS food was sparse, covering a narrow range of food groups, with no advertisements for fresh fruit or vegetables.

Conclusions: Despite the NP model having some design limitations in classifying real-world televised food advertisements, it was easily applied to this sample and could clearly identify HFSS products. Policy makers who do not wish to completely restrict food advertising to children outright should consider using this NP model for regulating food advertising.
\end{abstract}

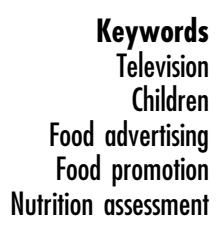

The recent population-wide increase in obesity has been explained in both public health and epidemiological disciplines by the increasing exposure to the 'obesogenic environment'. This environment is defined as 'the sum of the influences that the surroundings, opportunities, or conditions of life have on promoting obesity in individuals or populations ${ }^{,(1)}$. One component of this hazard is the frequent exposure of 'unhealthy' food advertising on television $^{(2-4)}$. Foods high in fat and/or sugar are the most commonly advertised foods in the $\mathrm{UK}^{(5)}$, the $\mathrm{USA}^{(6,7)}$ and Australia $^{(8,9)}$ during children's television viewing times. This pattern is replicated in New Zealand, with snack foods, sweet snacks, drinks and fast foods being the foods most commonly advertised to children ${ }^{(10-13)}$.

There is good evidence that food advertising influences food preference and purchase behaviour by children according to systematic reviews ${ }^{(14-16)}$. One rigorous review commissioned by the Institute of Medicine concluded that: 'Television advertising influences the food preferences, purchase requests, and diets, at least of children under age 12 years, and is associated with the increased rates of obesity among children and youth'(14). Another review concluded that studies of food preferences using experimental designs have consistently shown that children exposed to advertising will choose advertised food products at significantly higher rates than children who were not exposed ${ }^{(15)}$. A recent Australian survey examining children's exposure to television advertising of 'unhealthy' food reported an association of heavier and more frequent television viewing with more positive attitudes towards 'unhealthy' food and more frequent consumption of such food ${ }^{(16)}$. Data from a New Zealand longitudinal cohort study has further revealed an association between childhood television viewing and adult $\mathrm{BMI}^{(17)}$. Given these links between children's television viewing, their food preferences, consumption patterns and higher body weight, expert groups, including the International Obesity Taskforce ${ }^{(18)}$, have recommended limiting the marketing and advertising of foods and beverages to children. 
Recently there has been considerable dispute, between public health advocates and representatives of the food and marketing industries, over application of the term 'healthy' or 'unhealthy' to particular foods. The food and marketing industries argue that there is no such thing as 'healthy' or 'unhealthy' foods, only an 'unhealthy diet'(19). The food industry has also suggested that any system to classify single foods as 'healthy' or 'unhealthy' is likely to be so complex that it would be unwieldy and unworkable. However, the recent development of the UK Nutrient Profile (NP) model, designed for the purpose of regulating the television advertising of high-fat, high-salt and high-sugar (HFSS) foods, provides one potential model for identifying 'unhealthy' foods (in HFSS terms) ${ }^{(20)}$. As there has been no published 'field test' of this model to assess its practicality, we applied it to a data set of food advertisements from New Zealand television.

\section{Methods}

An advertising data set from New Zealand television was used because this country is actively engaging with how to limit the obesogenic environment (i.e. with a recent Select Committee Inquiry into Obesity and Type II Diabetes $)^{(21)}$. The country is also typical among developed nations in that the prevalence of adult obesity has doubled in the past 25 years ${ }^{(22)}$. National survey data also indicate that $9.8 \%$ of New Zealand children are obese and a further $21 \cdot 3 \%$ are overweight ${ }^{(23)}$. Indigenous Māori and Pacific Island children are particularly over-represented among those who are overweight or obese ${ }^{(23)}$.

\section{Channel and timing}

The New Zealand television media environment is dominated by three main free-to-air television channels. One of these (TV3) is privately owned, while the other two are state-owned (TV1 and TV2). Based on our strong impression from programming content, TV2 appears to be the channel with the more predominant child focus for weekday afternoon viewing. Therefore television on this channel was videotaped for the times when advertising is most likely to be targeted specifically at children (i.e. 15.30 hours to 18.30 hours on weekdays). The data collection dates spanned the four-week period from 25 June to 20 July 2007 (mid-winter in New Zealand), and totalled $60 \mathrm{~h}$. This four-week period also included two weeks of television programming running through a school holiday break.

\section{Type of advertisements}

Food advertisements were defined as all advertisements promoting a specific food or drink as well as generic food or beverage brand advertising (including advertisements for supermarkets, cafes and restaurants). 'Non-food advertisements' included all other advertisements. Data were not collected on promotions for television programmes (some of which contain food brands and food imagery) or on food imagery and verbal references within television programmes.

\section{The Nutrient Profile model}

Developed by the Food Standards Agency ${ }^{(20)}$, the NP model was adopted in 2007 by Ofcom (the UK regulatory body for communications industries) for the purposes of regulating the advertising of HFSS foods to children. The NP system identifies HFSS foods using a simple three-step scoring process based on nutrient components per $100 \mathrm{~g} /$ $100 \mathrm{ml}$ of food or drink. The numerical values assigned to the nutrient components in the scoring system are underpinned by the UK Dietary Guidelines for Recommended Daily Intakes. Foods and beverages are allocated points for four 'risk increasing' components: kilojoules, saturated fat, sugar and sodium; and points are then deducted for each of three 'risk decreasing' components: percentage of 'fruit, vegetables and nuts', fibre and protein (depending on the sum of the scores for the risk increasing components). Based on the final score calculated from this process, a food with a score of 4 or more, and beverage with a score of 1 or more, is classified as HFSS. The specific steps of the system are available online (http://www. food.gov.uk/healthiereating/advertisingtochildren/nutlab/ nutprofmod) and worked examples are provided in the Appendix.

\section{Collection of product nutritional information}

Where available, detailed data on the nutrient profiles of the advertised food and beverages were collected. Where practicable, nutrient data were obtained from the nutrition information panels printed on the back of the specific products advertised. This information was obtained via instore collection by the first author in a Wellington supermarket in August 2007. Nutrient data for other products were obtained, in the first instance, from company (brand) websites and their brochures, and in other instances from the Nutrition Information Panels website of the NZ Food Composition Database ${ }^{(24)}$. Occasionally more general websites were utilised to locate nutritional information not available from the above-mentioned sources.

\section{Issues in the collection of nutritional data}

Nutrient information on kilojoules, saturated fat, sugar, sodium and protein were readily available for most food products, while data on fibre and percentage of 'fruit, vegetables and nuts' were not. For fibre, data on New Zealand food labels and in the NZ Food Composition Database rely on the definition used by the American Association of Analytical Chemists ${ }^{(25)}$. However, as fibre content is not usually available for most products (there is no legal requirement for this on NZ food labels), we estimated the fibre content of some foods (burgers and pizzas) using the data from the generic brands found on 
the NZ Food Composition Database (e.g. in the present analysis it was estimated that all pizzas and burgers had $2 \mathrm{~g}$ fibre/100 g).

Data on the percentage of 'fruit, vegetables and nuts' per $100 \mathrm{~g}$ of food are not readily detailed on most advertised products. This information is required for calculating the scores under the NP model and there is supplementary documentation outlining the method for estimating the fruit, vegetable and nut content of food and beverages ${ }^{(26)}$. We did not formally attempt to estimate the fruit, vegetable or nut content of any product as it seemed very unlikely that any of the foods we analysed would meet the $40 \%$ criteria (per $100 \mathrm{~g}$ of food or $100 \mathrm{ml}$ of drink) which would result in a change to the final NP scores.

For practical reasons, all fast-food 'mixed meal' advertisements (burger or 'meal combos'), which included McDonalds, Pizza Hut, Dominoes Pizza, KFC, Burger King and Burger Fuel, were classified using the NP scores from the main component of the meal (burger, pizza or chicken). Methodological issues encountered in calculating NP scores for 'mixed meal' items are examined later.

\section{Results}

In the present sample of afternoon television, there were 1893 television advertisements of which 483 (25.5\%) were for food or food retailer outlets. Of these 483 advertisements, there were ninety-two unique food advertisements identified. That is, the specific advertisements were repeated, on average, $5 \cdot 3$ times during this $60 \mathrm{~h}$ sampling period (range: 1 to 28 showings). The sources of nutrient information for these ninety-two food advertisements were: nutrition information panels printed on the back of the specific products advertised ( $n$ 40), company (brand) websites and their brochures ( $n$ 26), Nutrition Information Panels website of the NZ Food Composition Database $(n 12)^{(24)}$ and more general webbased data sources ( $n$ 9). No nutrient profile information was possible for the five retailer advertisements.

Summary data on the proportion of foods classified as HFSS by the NP model are provided in Table 1 .

of the ninety-two distinct food advertisements, the application of the NP model resulted in $66 \%$ being classified as HFSS products and $28 \%$ as non-HFSS products. The unclassifiable advertisements were for restaurants or retailers

Table 1 Proportion and number of distinct televised food advertisements in the present study ( $n$ 92) classified as "high-fat, highsalt and high-sugar' (HFSS) by the UK Nutrient Profile (NP) model

\begin{tabular}{lcc}
\hline Summary category & Proportion (\%) & Number \\
\hline HFSS & $66 \cdot 3$ & 61 \\
Non-HFSS & $28 \cdot 3$ & 26 \\
Unclassifiable & $5 \cdot 4$ & 5 \\
Total & 100 & 92 \\
\hline
\end{tabular}

${ }^{*}$ Food retailer advertisements (that do not focus on specific food products). where either: (i) a combination of HFSS and non-HFSS products was promoted (e.g. as in supermarket retailer advertisements); or (ii) no specific food was advertised (e.g. in an advertisement for an Indian restaurant). On occasion, the imagery within these restaurant or retailer advertisements implied the promotion of one or more HFSS products. In our analysis we did not classify this as explicit advertising, although we recognise this as a potentially grey area.

The retailer, product and brand details of the ninetytwo food advertisements are listed in Table 2, ordered by NP score.

Table 2 shows a predominance of fast-food 'mixed meal' advertisements, most of which are classified as HFSS (with the exception of some Subway advertisements for filled sandwich rolls). In considering the repeat screening of food advertisements (final column), fast-food franchises (identified by an asterisk) advertising HFSS foods accounted for a majority, 53\% (169/321), of all the HFSS advertisements. Advertisements for HFSS cereals, HFSS snack bars and HFSS confectionery were also common. It was notable that there was no advertising for ice cream or frozen confectionery although this is not surprising given that our data collection period was over the winter months.

Types of food advertisements classified as non-HFSS under the NP model were predominantly for cereals, drinking yoghurts, home-cooked 'mixed meals' (e.g. advertisements for roast chicken or stir-fry meals), artificially sweetened drinks and chewing gums. There was a complete absence of any advertising for fresh fruit, vegetables or nuts. Also, the profile of the food considered as non-HFSS by the NP model could still be regarded as nutritionally suboptimal. For instance, although non-HFSS, the following products do not offer any beneficial nutrients either: diet drinks, artificially sweetened confectionery and artificially sweetened chewing gum. Furthermore, such diet drinks may displace milk consumption. Moreover, some of the homecooked 'mixed meals' promoted in recipe advertisements (e.g. 'Food in a Minute' recipes sponsored by a large food manufacturer) should probably not be considered as nonHFSS given that they contain additional foods of a mixed nutritional profile. Exactly how the HFSS rules are to be applied to particular cuts of meat, and whether they should also take into account the promotion of particular cooking methods (e.g. deep frying compared with grilling) is not clear, although there does appear to be ongoing discussion by the Ofcom regulators on this issue.

The impact of applying the NP model to all of the advertisements (and considering repeat showings of the same advertisement) is shown in Table 3. It shows that applying the NP model to this data set would result in $66 \%$ being classified as HFSS and hence potentially being restricted.

The present study also provides an updated estimate for the total exposure level of children to food advertising in New Zealand. On the basis of these data (321 HFSS 
Table 2 Details of the distinct televised food advertisements ( $n$ 92) with their ranked scores by the UK Nutrient Profile model (NP score) and final classification

\begin{tabular}{|c|c|c|c|c|}
\hline Retailer & Product and brand & NP score & Classification & No. of times shown \\
\hline Cadbury & Moro Gold (confectionery) & 36 & HFSS & 3 \\
\hline Flora & Pro Active (margarine spread) & 30 & HFSS & 2 \\
\hline Ferrero & Bueno-Kinder (confectionery) & 28 & HFSS & 2 \\
\hline Mars & Maltesers (confectionery) & 27 & HFSS & 12 \\
\hline Nestlé & Kit Kat (confectionery) & 27 & HFSS & 2 \\
\hline Cadbury & Dairy Milk (confectionery) & 26 & HFSS & 4 \\
\hline Cadbury & Crunchie (confectionery) & 26 & HFSS & 3 \\
\hline Cadbury & Cadbury Desserts (confectionery) & 25 & HFSS & 3 \\
\hline Kellogg's & LCM's Shakes cereal bars & 24 & HFSS & 1 \\
\hline Kellogg's & Nutrigrain bar & 22 & HFSS & 28 \\
\hline Cadbury & Crunch bar (confectionery) & 22 & HFSS & 1 \\
\hline Ferrero & Nutella (nut spread) & 21 & HFSS & 4 \\
\hline Watties FIMt & Fruit jelly & 20 & HFSS & 5 \\
\hline Bertolli & Extra virgin olive oil & 20 & HFSS & 2 \\
\hline Kellogg's & Crunchy nut nutty bar & 20 & HFSS & 1 \\
\hline Arnotts & Shapes crackersł & 18 & HFSS & 1 \\
\hline Burger King* & Transformers Kids' Meal & 17 & HFSS & 28 \\
\hline Mars & Snickers (confectionery) & 17 & HFSS & 5 \\
\hline Burger King* & Meal \& Coke & 17 & HFSS & 4 \\
\hline Aunt Betty & Puddingsł & 17 & HFSS & 2 \\
\hline Wrigley's & Solano candy (confectionery) & 17 & HFSS & 1 \\
\hline Pizza Hut* & Cheesy bites pizza \& Pepsi & 16 & HFSS & 27 \\
\hline Kellogg's & Nutrigrain cereal & 15 & HFSS & 1 \\
\hline Ferrero & Tic Tac (confectionery) & 14 & HFSS & 2 \\
\hline $\mathrm{KFC}^{*}$ & Lunchbox deal & 13 & HFSS & 13 \\
\hline $\mathrm{KFC}^{*}$ & Family meal \& Pepsi & 13 & HFSS & 7 \\
\hline Uncle Toby & Oats (a breakfast cereal) & 13 & HFSS & 5 \\
\hline $\mathrm{KFC}^{*}$ & KFC meal \& Pepsi & 13 & HFSS & 3 \\
\hline $\mathrm{KFC}^{*}$ & KFC meal \& Pepsi & 13 & HFSS & 2 \\
\hline Natural Conf Co. & Liquorice sticks (confectionery) & 13 & HFSS & 1 \\
\hline McDonalds* & Happy Meal & 12 & HFSS & 15 \\
\hline Dominoes Pizza* & Meat pie pizza & 12 & HFSS & 14 \\
\hline McDonalds* & Bacon/BBQ cheeseburger & 12 & HFSS & 10 \\
\hline McDonalds* & Hamburgers & 12 & HFSS & 4 \\
\hline McDonalds* & McDonalds after 5 deals & 12 & HFSS & 1 \\
\hline Watties FIMt & Malaysian stir fry & 11 & HFSS & 3 \\
\hline McCains & Pizza Subs & 11 & HFSS & 3 \\
\hline Pams & Fish marinera - recipe & 11 & HFSS & 1 \\
\hline Nestlé & Nesquick cereal & 10 & HFSS & 16 \\
\hline Nestlé & Milo cereal & 10 & HFSS & 10 \\
\hline Continental & Wholegrain pasta \& sauce & 10 & HFSS & 3 \\
\hline Burger Fuel* & Burger & 10 & HFSS & 2 \\
\hline Kellogg's & Special K cereal & 10 & HFSS & 1 \\
\hline Dominoes Pizza* & Spicy chicken pizza & 9 & HFSS & 20 \\
\hline Dominoes Pizza* & Pizza 1970s range & 9 & HFSS & 13 \\
\hline Nestlé & Cheerios cereal & 9 & HFSS & 3 \\
\hline Maggi & Cheese sauce & 9 & HFSS & 1 \\
\hline Old El Paso & Hard ' $n$ ' soft taco kit & 6 & HFSS & 1 \\
\hline Kings & Traditional soup mix & 6 & HFSS & 1 \\
\hline Watties FIMt & Breaded butter pudding & 5 & HFSS & 2 \\
\hline Subway* & Roast lamb sub & 4 & HFSS & 8 \\
\hline Watties FIMt & Cottage pie & 4 & HFSS & 5 \\
\hline Pataks & Pataks cashew chicken & 4 & HFSS & 5 \\
\hline Wrigley's & Eclipse ice gum (confectionery) & 4 & HFSS & 4 \\
\hline Wendy's* & Hamburgers & 4 & HFSS & 1 \\
\hline Splenda & Splenda (artificial sweetener) & 4 & HFSS & 1 \\
\hline Campbells & Real beef stock & 4 & HFSS & 1 \\
\hline Fresh n Fruity & Splatz yoghurt & 3 & Non-HFSS & 12 \\
\hline Watties FIMt & Roast pork loin & 3 & Non-HFSS & 2 \\
\hline Subway* & Steak $\&$ cheese sub & 3 & Non-HFSS & 2 \\
\hline Wrigley's & Extra gum (sugar-free gum) & 3 & Non-HFSS & 1 \\
\hline Subway* & Blackened cajun steak sub & 3 & Non-HFSS & 1 \\
\hline Coca-Cola & Coke (drink) & 2 & HFSS & 9 \\
\hline Red Bull & Red Bull (drink) & 2 & HFSS & 2 \\
\hline Coca-Cola & Lift plus (drink) & 2 & HFSS & 2 \\
\hline McCains & Healthy Choice Frozen meals & 2 & Non-HFSS & 1 \\
\hline Maggi & Feel Good Soup & 2 & Non-HFSS & 1 \\
\hline Kraft & Chicken Easy Macaroni & 2 & Non-HFSS & 1 \\
\hline Subway* & Sub \& Coke zero meal & 1 & Non-HFSS & 16 \\
\hline
\end{tabular}


Table 2 Continued

\begin{tabular}{|c|c|c|c|c|}
\hline Retailer & Product and brand & NP score & Classification & No. of times shown \\
\hline Coca-Cola & Powerade (drink) & 1 & HFSS & 2 \\
\hline Carnation & Light/creamy coconut milk & 1 & Non-HFSS & 2 \\
\hline Greggs & Cafe gold (coffee) & 0 & Non-HFSS & 21 \\
\hline Anchor & Calci-yum squeeziblesł & 0 & Non-HFSS & 12 \\
\hline Coca-Cola & Coke Zero (diet drink) & 0 & Non-HFSS & 5 \\
\hline Just Juice & Bubbles (drink) & 0 & Non-HFSS & 2 \\
\hline Pepsi & Pepsi Max (carbonated drink) & 0 & Non-HFSS & 1 \\
\hline Campbells & Sensations tomato soup & 0 & Non-HFSS & 1 \\
\hline Bell & Tea & 0 & Non-HFSS & 1 \\
\hline Sanitarium & Honey Puffs (a breakfast cereal) & -1 & Non-HFSS & 11 \\
\hline Tip Тop & Goodness grains bread & -2 & Non-HFSS & 4 \\
\hline Watties FIMt & Tegal Boneless roast & -3 & Non-HFSS & 2 \\
\hline Tegal & Boneless roast & -3 & Non-HFSS & 1 \\
\hline Tegal & Tegal roast & -3 & Non-HFSS & 1 \\
\hline Sanitarium & Weet-Bix (a breakfast cereal) & -4 & Non-HFSS & 26 \\
\hline Anchor & Milkł & -4 & Non-HFSS & 2 \\
\hline Inghams & Chicken Kiev & -7 & Non-HFSS & 2 \\
\hline Harraways & Oat Singles (cereal portions) & -7 & Non-HFSS & 2 \\
\hline Countdown & Supermarket (retailer) & $\mathrm{U}$ & $\mathrm{U}$ & 5 \\
\hline McDonalds* & McCafe (retailer) & U & U & 3 \\
\hline Wild Bean Café & Café (retailer) & $U$ & $\mathrm{U}$ & 1 \\
\hline Valentines & Restaurant (retailer) & U & $\mathrm{U}$ & 1 \\
\hline Little India & Restaurant (retailer) & U & U & 1 \\
\hline
\end{tabular}

HFSS, 'high-fat, high-salt and high-sugar'; U, unclassifiable using the NP model.

${ }^{*}$ Fast-food franchises.

†'Watties FIM': these were 'Food in a Minute' recipe demonstration advertisements sponsored by Watties. $\ddagger$ Not specified which variety/flavour.

Table 3 All food advertisements in the present data set ( $n$ 483) classified by the UK Nutrient Profile model (including repeat showings)

\begin{tabular}{lcc}
\hline Classification & Proportion (\%) & Number \\
\hline HFSS & $66 \cdot 5$ & 321 \\
Non-HFSS & $31 \cdot 2$ & 151 \\
Unclassifiable & $2 \cdot 3$ & 11 \\
Total & $99 \cdot 9^{*}$ & 483 \\
\hline
\end{tabular}

*Percentage not equal to 100 because of rounding.

advertisements over $60 \mathrm{~h}$ ) and data on New Zealand children's viewing patterns, which suggest that an average child watches television for $2 \mathrm{~h}$ each day ${ }^{(27)}$, an average child would potentially see around fifty-four HFSS product advertisements per week from weekday afternoon television alone.

\section{Discussion}

\section{Major findings}

In general, the UK NP model was easily applied to television advertising in New Zealand, another Englishspeaking developed country. As far as we are aware, this is the first such 'field test' of this model. More importantly, from a public health nutrition perspective, this model was able to identify HFSS product advertising although a proportion of non-HFSS advertisements were still suboptimal in nutritional terms.

Based on our sample, the implementation of regulations based on the NP model would result in a large about reduction (about two-thirds) of food advertising during weekday afternoon television. This would dramatically reduce children's exposure to the advertising of HFSS products.

Consistent with other content analyses of food advertising to children ${ }^{(5-13)}$, the majority of food advertised in our New Zealand sample was for HFSS products. The largest proportion $(53 \%)$ of these HFSS advertisements was for 'mixed meal' combos promoted by the major fast-food franchises. Other HFFS foods frequently promoted included cereals, confectionery and carbonated beverages.

Carbonated beverages were mostly promoted as part of a meal combo rather than as a singular product. However, because we used the nutrient information for the main component of the mixed meal (i.e. the burger, not the fries or the drink), the frequency at which carbonated beverages are promoted in our sample is under-reported. In fact, if advertisements where carbonated beverages were promoted as part of a mixed meal combo were combined with advertisements where they were promoted as a single item, carbonated beverages become the most frequently promoted product in our sample. Given the contribution of carbonated beverages to poor childhood oral health (due to their high sugar or acid content in 'diet' brands), childhood obesity ${ }^{(28)}$ and detrimental effects on Ca levels by displacing milk consumption ${ }^{(29,30)}$, this advertising constitutes a particular concern from a public health perspective.

In contrast, the advertising of non-HFSS foods was sparse, covering only a narrow range of food groups such as cereals, drinking yoghurts, home-cooked 'mixed 
meals', artificially sweetened confectionery or drinks, and a small number of single recipe items (not generally intended for consumption on their own). The total lack of advertising for fruits and vegetables is consistent with international trends ${ }^{(31)}$. The absence of advertising for other nutritionally desirable foods, such as nuts, legumes and 'low-fat, low-sugar' dairy products, is also problematic from a public health perspective. There was also an absence of advertising of nutrient-rich foods that are traditional to Māori and Pacific peoples (e.g. kumara, fresh seafood and tropical fruits).

\section{Methodological issues with mixed meals}

Since the HFSS food advertising was dominated by the fast-food sector, which almost always promoted 'mixed meal' combos, it is important to consider some of the methodological issues we encountered in classifying these types of food advertisements.

In the absence of additional instructions for applying the UK NP model to real-world advertisements, we were required to make some judgement calls on how to deal with mixed meal items that contained foods of mixed nutritional profiles. For instance, in the present analysis we adopted a conservative approach, using only the NP scores of the main component of the meal. A more health-focused approach would have classified the mixed meal items using the NP scores from the most nutritionally hazardous (or highest $\mathrm{kJ}$ ) component of the meal combo. Another approach could have used the NP scores from all the items combined. We did not see these options as practical for the following reasons.

Classifying mixed meal combos by the NP score of the most nutritionally hazardous item would have, in many cases, resulted in classifying the advertisements by the NP score of the deep-fried chips. We explored this in a separate analysis which revealed that the NP scores for the deep-fried chips ranged, depending on the brand, from 8 to 20. As these scores are still well over the NP score threshold of 4 , they would not have altered the resulting categorisation of the mixed meal combo as an HFSS product.

An alternative method, creating a summary score from the various foods within a mixed meal, was also explored. However, this was not feasible as the final NP scores for identifying HFSS products are set at a different level for food and drink. Another difficulty relates to the classification of diet drinks as non-HFSS while the full-sugar variety of the same brand is classified as HFSS. This was a problem as many of the advertisements we analysed did not distinguish between the full-sugar or artificially sweetened variety.

A similar difficulty was encountered in classifying home-cooked 'mixed meal' items. While we are aware that there has been some discussion by Ofcom regulators in the UK over whether particular meat cuts should be subject to HFSS rules, we are not aware of any published guidelines on this matter. Nor are we aware of any rules which relate to the promotion, in television advertising, of health-promoting $v$. potentially hazardous cooking methods that may impact on the nutrient profiles and carcinogen levels in food. Potentially, cooking methods that result in high saturated fat content or charring of food could be included in upgraded evidence-based rules produced by regulators.

Finally, consideration should be given to the correct categorisation of recipe items or ingredients. Although this was not a problem in our sample, it is possible to imagine a number of scenarios where the classification of some food items may cause some controversy. For instance, products such as Vegemite (which has high sodium per $100 \mathrm{~g}$ ) and olive oil will be classified as HFSS products although they are not considered problematic in nutritional terms. Whether such products should be 'exempted' or subject to different rules is an issue for policy makers to consider. Similarly, there may be an argument, given the total lack of advertising for fruit and vegetables, to support the exemption of these foods from food advertising regulations.

\section{Study limitations}

The present study was based on data from just one television channel, albeit probably the most popular free-toair one for children in New Zealand. An even more thorough study would have considered other free-to-air channels and pay television channels oriented towards children (e.g. Disney Channel).

The study was based on just four weeks of afternoon weekday television in one season (winter). Seasonal variations in the advertising of some foods have been noted by us (see earlier for frozen confectionery) and competing advertising and other food advertising may also vary during the year (e.g. toy advertising and gift food advertising in the months before Christmas and chocolate/buns around Easter). This study also included a two-week period of school holidays. As such, it may not be typical of the rest of the year and may underestimate typical levels of food advertising. A more extensive analysis would also consider advertisements in early morning and weekend television as many of these are also aimed at children, albeit at a lower hourly rate ${ }^{(13)}$.

We have assumed that the nutrient information we have obtained is reasonably accurate and that the sources we used to obtain the data are legitimate. We note, however, that in New Zealand the Consumers' Institute has highlighted an inconsistency between nutrient information as stated on the food labels compared with the actual nutrients in the products ${ }^{(32)}$. In particular, a recent survey by the Institute indicated that some products had sodium levels that 'seriously exceeded their label claims ${ }^{(33)}$. This issue does not affect the integrity of the NP model, but it does suggest there is a need to monitor compliance with NP claims made by manufacturers. 
We did not attempt to estimate the proportion of 'fruit, vegetables and nuts' in the advertised products. However, we think that this omission is very unlikely to have affected our results as the food groups predominantly advertised would appear to be well below the $40 \%$ criterion required to alter the final NP scores. Similarly, we were unable to obtain information on fibre in many cases because there is no requirement (under NZ regulations) to include this information on labels. As noted in the Methods section, we did not expect the advertised foods to contain any substantial level of fibre, with the exception of perhaps pizzas and burgers, for which we estimated the fibre content as they were so frequently advertised.

\section{Implications for furtber research}

As our study was only based on advertisements from a four-week winter period in one country, it would be desirable to have multi-season and multi-country studies to better assess the practicality and impact of the NP model. It would also assist research in this area to obtain forthcoming evaluation data on how the NP model has worked in practice in the UK to date.

We would also suggest that there is clearly a need for routine surveillance of food advertising on television across multiple channels. Such data would provide baseline information critical for assessing the success of any future self-regulatory or government-mandated advertising regulations. Baseline data that would be critical to monitoring changes to food advertising should include number and length of food advertisements, 'in-programme promotions' (explicit promotions often within local children's television programmes), sponsorship of programmes, product placement advertising, giveaway incentives (toys and competitions), and brand and retailer advertising. Studies of food marketing and food sponsorship in other media (e.g. the Internet) should be conducted simultaneously, as these forms of marketing are likely to expand in the future if television advertising becomes subject to regulation.

\section{Policy implications}

Until now, one of the barriers faced by policy makers wishing to reduce children's exposure to the advertising of energy-dense nutrient-poor foods was the lack of a robust instrument for differentiating such foods. The UK NP model was able to identify HFSS food advertising, but not all products that would be considered as undesirable from a public health nutrition perspective. Diet drinks, for instance, are classified as non-HFSS but are still suboptimal nutritionally. Similarly, some foods such yeast spreads and olive oils would be classified as HFSS but may not be considered as suboptimal nutritionally, as they contain important nutrients and are generally only used sparingly.

Our study shows that the model used by Ofcom can be easily and readily applied to real-world food advertisements.
We found the universal nutrient criteria applied to all products at the $100 \mathrm{~g} / 100 \mathrm{ml}$ base was simple to use compared with category-specific nutrient profile models requiring separate nutritional criteria. Categorical nutrient profile models also involve a degree of subjective interpretation over which category a product belongs to, which is potentially open to dispute.

If policy makers wish to adopt this model for the purpose of regulating food advertising to protect child health, they will need to consider a number of factors. In particular it would be critical, in terms of reducing children's exposure to HFSS food advertising, to be clear on the television viewing times for children (not just standard time slots suggested by broadcasters). We think it is wise to have children's television viewing times and patterns assessed by a survey that is independent of television broadcasters, advertisers and media-associated industries. This would ensure that restrictions can be applied to appropriate viewing times and facilitate public confidence that the findings are free from vested interests.

Other forms of marketing used by the manufacturers of HFSS products (such as in-school marketing, sponsorship, and on the Internet) should also be monitored, with consideration given to implementing regulations in these areas before they become more problematic. As well as monitoring the range of marketing mechanisms, it is possible that the NP model could be applied, with some minor modification (i.e. translation of NP scores into 'traffic light' symbols), to the regulation of food labelling or front-of-pack signposting to assist consumers to easily identify HFSS foods. Some countries already have experience with regulation in this general area (e.g. mandatory symbols on electrical appliances indicating levels of energy efficiency in Australia and New Zealand).

Another concern is the allowance, under the current Ofcom rules, for continued food retailer advertising. This is potentially problematic from a public health perspective, given that half of the HFSS advertisements in our sample were attributable to fast-food retailers' promotion of HFSS products. This level of fast-food promotion is inconsistent with advice from the International World Cancer Research Fund to 'consume fast food sparingly, if at all'(34).

Another policy option, albeit a politically challenging one, is to consider complete restrictions on all food advertising during children's television viewing time (e.g. when at least $10 \%$ of the audience is under age 16 years). This would be much simpler to apply, and could reasonably be justified on the grounds that much of the non-HFSS food advertised tends to be (and was in our sample) for food that is still suboptimal in nutrition terms. At the same time there could be an exemption for social marketing campaigns that promote fruit and vegetable consumption. Policy makers can also draw on ethical arguments around the protection of children to support complete restrictions on all advertising to children, as has been done to justify this approach in Sweden ${ }^{(35,36)}$, Norway and Quebec, Canada ${ }^{(27)}$. 


\section{Conclusions}

The NP model was specifically designed for the purpose of regulating food advertising to children in the UK. Our study, based on four weeks of weekday afternoon television on a popular child-centred New Zealand television channel, examined the practicality and applicability of the NP model to real-world food advertising. We found it relatively easy to apply the NP model to this data set of food advertising and it was able to identify HFSS products. However, some of the non-HFSS products were still suboptimal nutritionally. Some clear guidelines regarding the methodological issues we have highlighted would be useful, in particular on classifying 'mixed meal' items, to ensure ease of classification and consistency in categorising HFSS products. Other minor modifications could also be made to improve how easily the NP model is operationalised. This would help policy makers and regulators minimise resource-wasting demarcation disputes.

\section{Acknowledgements}

The present research was fully funded by the New Zealand Ministry of Health. Nevertheless, the views expressed are those of the authors and do not necessarily represent Ministry of Health views or policies. Helpful advice and comment on various issues were provided by Louise Signal, Carolyn Watts and Mat Walton of the University of Otago, Wellington; and Caroline Shaw of the Ministry. However, these reviewers may also not necessarily agree with all aspects of the final content. We would also like to thank the journal's two anonymous reviewers for their helpful comments.

Competing interests: One of the authors (N.W.) has previously undertaken work on nutrition issues for nonprofit non-governmental organisations. The other authors declare no competing interests.

Authorship responsibilities: The study was designed by N.W. and G.J. Data collection and coding was by N.H. and G.J. The analyses were conducted by G.J. All coauthors contributed in writing of the drafts and agree to the form of the final paper. G.J. is the guarantor.

\section{References}

1. Swinburn B, Egger G \& Raza F (1999) Dissecting obesogenic environments: the development and application of a framework for identifying and prioritizing environmental interventions for obesity. Prev Med 29, 563-570.

2. Hill JO \& Peters JC (1998) Environmental contributions to the obesity epidemic. Science 280, 1371.

3. Lobstein T \& Dibb S (2005) Evidence of a possible link between obesogenic food advertising and child overweight. Obes Rev 6, 203-208.
4. Swinburn B \& Egger G (2004) The runaway weight gain train: too many accelerators, not enough brakes. BMJ 329, 736-739.

5. Lewis MK, Hill AJ, Taras HL \& Gage M (1998) Food advertising on British children's television: a content analysis and experimental study with nine-year olds. Int $J$ Obes Relat Metab Disord 22, 206-214.

6. Powell LM, Szczypka G, Chaloupka FJ \& Braunschweig CL (2007) Nutritional content of television food advertisements seen by children and adolescents in the United States. Pediatrics 120, 576-583.

7. Taras HL \& Gage M (1995) Advertised foods on children's television. Arch Pediatr Adolesc Med 149, 649-652.

8. Chapman K, Nicholas P \& Supramaniam R (2006) How much food advertising is on Australian television? Health Promot Int 21, 172-180.

9. Kelly B, Smith B, King L, Flood V \& Bauman A (2007) Television food advertising to children: the extent and nature of exposure. Public Health Nutr 10, 1234-1240.

10. Hammond KM, Wyllie A \& Casswell S (1999) The extent and nature of televised food advertising to New Zealand children and adolescents. Aust N Z J Public Health 23, 49-55.

11. McClean H \& Knowles S (1992) Television advertising of foods to children in NZ. J $N Z$ Diet Assoc 46, 11-13.

12. Wilson N, Quigley R \& Mansoor O (1999) Food ads on TV: a health hazard for children? Aust N Z J Public Health 23, 643-650.

13. Wilson N, Signal L, Nicholls S \& Thomson G (2006) Marketing fat and sugar to children on New Zealand television. Prev Med 42, 96-101.

14. McGinnis M, Gootman J \& Kraak V (2006) Food Marketing to Children and Youth: Threat or Opportunity? Washington, DC: National Academies Press.

15. Coon KA \& Tucker KL (2002) Television and children's consumption patterns. A review of the literature. Minerva Pediatr 54, 423-436.

16. Dixon HG, Scully ML, Wakefield MA, White VM \& Crawford DA (2007) The effects of television advertisements for junk food versus nutritious food on children's food attitudes and preferences. Soc Sci Med 65, 1311-1323.

17. Hancox RJ, Milne BJ \& Poulton R (2004) Association between child and adolescent television viewing and adult health: a longitudinal birth cohort study. Lancet 364, $257-262$.

18. International Obesity Taskforce (2007) The Sydney Principles: Guiding principles for achieving a substantial level of protection for children against the commercial promotion of foods and beverages. http://www.iotf.org/sydneyprinciples/ (accessed April 2008).

19. Food Standards Agency (2007) Summary of nutrient profiling review panel's responses to stakeholder comments. http:// www.food.gov.uk/multimedia/pdfs/npresponses0710.pdf (accessed April 2008).

20. Food Standards Agency (2006) The nutrient profiling model. http://www.food.gov.uk/healthiereating/advertisingtochildren/ nutlab/nutprofmod (accessed September 2007).

21. Health Select Committee (2007) Inquiry into Obesity and Type II Diabetes in New Zealand. Wellington: Forty-eighth Parliament.

22. Ministry of Health (2004) Tracking the Obesity Epidemic: New Zealand 1977-2003. Report no. 24. Wellington: Ministry of Health.

23. Ministry of Health (2003) NZ Food NZ Children: Key Results of the 2002 National Children's Nutrition Survey. Wellington: Ministry of Health.

24. Ministry of Health, Crop \& Food Research (2007) New Zealand Food Composition Database: Nutrition Information Panel Database. http://www.crop.cri.nz/home/products-services/ nutrition/foodcompdata/fcd-products/fcd-nutrition-database.jsp (accessed September 2007). 
25. Association of Official Analytical Chemists (1990) Official Methods of Analysis of the Association of Official Analytical Chemists, 15th ed., vol. II, sec. 985.29. Arlington, VA: AOAC.

26. Scarborough P, Rayner M, Boxer A \& Stockley L (2005) Application of the Nutrient Profiling Model: Definition of 'Fruit, Vegetables and Nuts' and Guidance on Quantifying the Fruit, Vegetable and Nut Content of a Processed Product. Oxford: Department of Public Health, University of Oxford.

27. Obesity Action Coalition (2007) Would You Like Lies With That? Food, Kids and TV Advertising. Wellington: Obesity Action Coalition.

28. Ludwig DS, Peterson KE \& Gortmaker SL (2001) Relation between consumption of sugar-sweetened drinks and childhood obesity: a prospective, observational analysis. Lancet 357, 505-508.

29. James J, Thomas P, Cavan D \& Kerr D (2004) Preventing childhood obesity by reducing consumption of carbonated drinks: cluster randomised controlled trial. BMJ 328, $1237-1242$.
30. Skinner JD, Bounds W, Carruth BR \& Ziegler P (2003) Longitudinal calcium intake is negatively related to children's body fat indexes. J Am Diet Assoc 103, 1626-1631.

31. Kaiser Family Foundation (2007) Food for Thought: Television Food Advertising to Children in the United States. Washington, DC: Kaiser Family Foundation.

32. Allan B (2006) Food labelling: In our view. Consumer. org.nz, 30 January.

33. Consumers' Institute (2007) Sodium labelling. Consumer. org.nz, 27 July.

34. World Cancer Research Fund \& American Institute for Cancer Research (2007) Food, Nutrition, Physical Activity, and the Prevention of Cancer: A Global Perspective. Washington, DC: AICR.

35. Caraher M, Landon J \& Dalmeny K (2005) Television advertising and children: lessons from policy development. Public Health Nutr 9, 596-605.

36. Hawkes C (2004) Marketing Food to Children: The Global Regulatory Environment. Geneva: WHO.

\section{Appendix: The UK Nutrient Profile classification system (with worked examples)}

\section{Step 1}

Work out total 'A' points (a maximum of 10 points can be awarded for each nutrient):

Total 'A' points $=($ points for energy + points for saturated fat + points for sugar + points for sodium $)$.

The following table indicates the points scored depending on the content of each nutrient in $100 \mathrm{~g}$ of food.

Table A1 Details of the scoring system used in the UK Nutrient Profile classification system

\begin{tabular}{|c|c|c|c|c|c|c|c|c|c|c|c|}
\hline Points & 0 & 1 & 2 & 3 & 4 & 5 & 6 & 7 & 8 & 9 & 10 \\
\hline Energy (kJ) & $\leq 335$ & $>335$ & $>670$ & $>1005$ & $>1340$ & $>1675$ & $>2010$ & $>2345$ & $>2680$ & $>3015$ & $>3350$ \\
\hline Saturated fat $(\mathrm{g})$ & $\leq 1$ & $>1$ & $>2$ & $>3$ & $>4$ & $>5$ & $>6$ & $>7$ & $>8$ & $>9$ & $>10$ \\
\hline Total sugar $(\mathrm{g})$ & $\leq 4 \cdot 5$ & $>4.5$ & $>9$ & $>13 \cdot 5$ & $>18$ & $>22 \cdot 5$ & $>27$ & $>31$ & $>36$ & $>40$ & $>45$ \\
\hline Sodium (mg) & $\leq 90$ & $>90$ & $>180$ & $>270$ & $>360$ & $>450$ & $>540$ & $>630$ & $>720$ & $>810$ & $>900$ \\
\hline
\end{tabular}

If a food or drink scores 11 or more 'A' points, then it cannot score points for protein unless it also scores 5 points for 'fruit, vegetables and nuts'.

\section{Step 2}

Work out total 'C' points:

Total 'C' points $=($ points for fruit, vegetables $\&$ nut content $)+$ points for fibre + points for protein.

The following table indicates the points scored, depending on the content of each nutrient/food component in $100 \mathrm{~g}$ of the food.

Table A2 Additional points in the UK Nutrient Profile classification system

\begin{tabular}{|c|c|c|c|c|c|c|}
\hline Points & 0 & 1 & 2 & 3 & 4 & $5+$ \\
\hline Fruit, vegetables and nuts (\%) & $\leq 40$ & $>40$ & $>60$ & - & - & $>80$ \\
\hline AOAC fibre* $(\mathrm{g})$ & $\leq 0.9$ & $>0.9$ & $>1.9$ & $>2 \cdot 8$ & $>3 \cdot 7$ & $>4.7$ \\
\hline Protein $(\mathrm{g})$ & $\leq 1 \cdot 6$ & $>1 \cdot 6$ & $>3 \cdot 2$ & $>4 \cdot 8$ & $>6 \cdot 4$ & $>8 \cdot 0$ \\
\hline
\end{tabular}

AOAC, Association of Official Analytical Chemists.

*The UK Nutrient Profile model also has an alternative for including 'NSP fibre' which can be used in place of 'AOAC fibre' (although it is the later that is used in NZ food labelling).

If a food or drink scores 5 points for 'fruit, vegetables and nuts', the 'A' nutrient cut-off no longer applies.

Step 3

Work out overall score as detailed in the following steps.

- If a food or drink scores less than 11 'A' points then the overall score is calculated as follows:

$$
\text { Overall score }=\text { (total 'A' points) }- \text { (total 'C' points). }
$$


- If a food or drink scores 11 or more 'A' points but scores 5 points for 'fruit, vegetables and nuts', then the overall score is calculated as follows:

$$
\text { Overall score }=(\text { total 'A' points })-\text { (total 'C' points) }
$$

- If a food or drink scores 11 or more 'A' points but also scores less than 5 points for 'fruit, vegetables and nuts', then the overall score is calculated as follows:

$$
\begin{gathered}
\text { Overall score }=\text { (total 'A' points })- \text { (fibre points }+ \text { fruit, vegetables \& nuts points only }) \\
\text { [i.e. no points for protein]. }
\end{gathered}
$$

From all the steps detailed above, food is classified as 'less healthy' where it scores 4 points or more; and drink is classified as 'less healthy' where it scores 1 point or more. The following table shows some working examples using food

\begin{tabular}{|c|c|c|c|c|c|c|c|c|c|c|}
\hline \multirow[b]{2}{*}{ Brand/Food } & \multicolumn{5}{|c|}{ 'Risk increasing' components ('A' points) } & \multicolumn{4}{|c|}{ 'Risk decreasing' components ('C' points) } & \multirow[b]{2}{*}{$\begin{array}{c}\text { NP score } \\
(A-C)\end{array}$} \\
\hline & Energy (kJ) & $\begin{array}{l}\text { Saturated } \\
\text { fat }(\mathrm{g})\end{array}$ & $\begin{array}{c}\text { Total } \\
\text { sugar }(\mathrm{g})\end{array}$ & $\begin{array}{c}\text { Sodium } \\
\text { (mg) }\end{array}$ & $\begin{array}{c}\text { A } \\
\text { points }\end{array}$ & $\begin{array}{c}\mathrm{F} / \mathrm{V} / \mathrm{N}^{*} \\
(\%)\end{array}$ & $\begin{array}{c}\text { Fibre } \\
\text { (g) }\end{array}$ & $\begin{array}{l}\text { Protein } \\
\text { (g) }\end{array}$ & $\begin{array}{c}\mathrm{C} \\
\text { points }\end{array}$ & \\
\hline \multirow[t]{2}{*}{ Kellogg's/Nutrigrain cereal } & 1596 & $0 \cdot 1$ & $32 \cdot 0$ & 600 & & 0 & $2 \cdot 7$ & $21 \cdot 0$ & & \\
\hline & 4 & 0 & 7 & 6 & 17 & 0 & 2 & 5 & 2 & 15 \\
\hline \multirow[t]{2}{*}{ Burger King/hamburger } & 1072 & $10 \cdot 0$ & $5 \cdot 0$ & 462 & & & $2 \cdot 0$ & $13 \cdot 2$ & & \\
\hline & 3 & 9 & 1 & 5 & 18 & 0 & 1 & 5 & 1 & 17 \\
\hline \multirow[t]{2}{*}{ Pizza Hut/Cheesy bites } & 1110 & $6 \cdot 3$ & $4 \cdot 4$ & 740 & & & $1 \cdot 9$ & $12 \cdot 7$ & & \\
\hline & 3 & 6 & 0 & 8 & 17 & 0 & 1 & 5 & 1 & 16 \\
\hline \multirow[t]{2}{*}{ Sanitarium/Weet-Bix } & 1489 & 0.4 & 0.0 & 270 & & 0 & $17 \cdot 5$ & $14 \cdot 0$ & & \\
\hline & 4 & 0 & 0 & 2 & 6 & 0 & 5 & 5 & 10 & -4 \\
\hline \multirow[t]{2}{*}{ Dominoes Pizza/chicken pizza } & 1030 & $3 \cdot 4$ & $2 \cdot 7$ & 505 & & & $2 \cdot 0$ & $10 \cdot 4$ & & \\
\hline & 3 & 3 & 0 & 5 & 11 & 0 & 2 & 5 & 2 & 9 \\
\hline \multirow[t]{2}{*}{ Nestlé/Nesquick cereal } & 1605 & $1 \cdot 6$ & $31 \cdot 8$ & 233 & & 0 & $5 \cdot 1$ & $7 \cdot 4$ & & \\
\hline & 5 & 1 & 7 & 2 & 15 & 0 & 5 & 4 & 5 & 10 \\
\hline \multirow[t]{2}{*}{ McDonalds/hamburger } & 1080 & $4 \cdot 3$ & $5 \cdot 6$ & 588 & & & $2 \cdot 0$ & $13 \cdot 2$ & & \\
\hline & 3 & 4 & 1 & 6 & 14 & 0 & 2 & 5 & 2 & 12 \\
\hline \multirow[t]{2}{*}{ Dominoes Pizza/meat pie pizza } & 1110 & $4 \cdot 4$ & 3.9 & 634 & & & 2 & $10 \cdot 2$ & & \\
\hline & 3 & 4 & 0 & 7 & 14 & 0 & 2 & 5 & 2 & 12 \\
\hline \multirow[t]{2}{*}{$\mathrm{KFC/fried} \mathrm{chicken}$} & 1197 & $5 \cdot 1$ & $0 \cdot 3$ & 528 & & & $0 \cdot 8$ & $22 \cdot 6$ & & \\
\hline & 3 & 5 & 0 & 5 & 13 & 0 & 0 & 5 & 0 & 13 \\
\hline \multirow[t]{2}{*}{ Mars/Maltesers } & 2100 & $14 \cdot 0$ & $55 \cdot 0$ & 120 & & 0 & 0.0 & $6 \cdot 5$ & & \\
\hline & 6 & 10 & 10 & 1 & 27 & 0 & 0 & 4 & 0 & 27 \\
\hline \multirow{2}{*}{ Fresh n Fruity/Splatz } & 443 & 1.5 & $17 \cdot 0$ & 53 & & 0 & 0.0 & $4 \cdot 1$ & & \\
\hline & 1 & 1 & 3 & 0 & 5 & 0 & 0 & 2 & 2 & 3 \\
\hline \multirow[t]{2}{*}{ Anchor/Calci-yum } & 318 & $0 \cdot 8$ & $13 \cdot 3$ & 59 & & 0 & 0.0 & $3 \cdot 8$ & & \\
\hline & 0 & 0 & 2 & 0 & 2 & 0 & 0 & 2 & 2 & 0 \\
\hline \multirow[t]{2}{*}{ Red Bull/Full Sugar Drink } & 192 & 0.0 & $10 \cdot 7$ & 80 & & 0 & 0.0 & 0.0 & & \\
\hline & 0 & 0 & 2 & 0 & 2 & 0 & 0 & 0 & 0 & 2 \\
\hline \multirow[t]{2}{*}{ Coca-Cola/Coke Zero } & 1.4 & $0 \cdot 0$ & 0.0 & $11 \cdot 0$ & & 0 & 0 & 0 & & \\
\hline & 0 & 0 & 0 & 0 & 0 & 0 & 0 & 0 & 0 & 0 \\
\hline \multirow[t]{2}{*}{ Coca-Cola/Coke } & 180 & 0.0 & $10 \cdot 6$ & $10 \cdot 0$ & & 0 & 0 & 0 & & \\
\hline & 0 & 0 & 2 & 0 & 2 & 0 & 0 & 0 & 0 & 2 \\
\hline
\end{tabular}
advertising data from the present study (points shown in bold).

Table A3 Calculating scores according to the UK Nutrient Profile model (NP score)

${ }^{*} \mathrm{~F} / \mathrm{V} / \mathrm{N}$, 'fruit, vegetables and nuts'. 